\title{
Hızlandırılmış Yapay Yaşlandırma Uygulamasının CAD-CAM Materyallerinin Renklenmesi Üzerindeki Etkisi
}

\author{
Effect of Accelerated Artificial Aging on Color Stability of CAD-CAM Materials
}

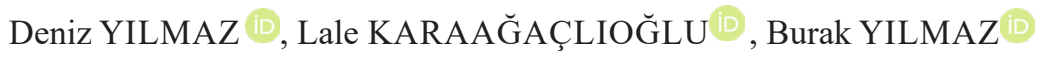

$\ddot{O} z$

Amaç: Farklı kimyasal kompozisyona sahip CAD-CAM bloklara uygulanan glaze ve mekanik parlatma işlemlerinin hızlandırılmış yapay yaşlandırma (AAA) uygulaması sonrası renklenme $\left(\Delta \mathrm{E}_{00}\right)$ üzerindeki etkisini değerlendirmek.

Gereç ve Yöntemler: Çalışmamız üç ana gruptan oluşmaktadır. CAD-CAM bloklarından (Vita Mark II, Vita Suprinity ve Vita Enamic) 50 örnek elde edilerek kimyasal kompozisyonlarına göre mekanik parlatma veya glaze teknikleri uygulanarak $\left(M_{p}\right.$, $\left.\mathrm{M}_{\mathrm{g}}, \mathrm{S}_{\mathrm{p}}, \mathrm{S}_{\mathrm{g}}, \mathrm{E}_{\mathrm{p}}\right) 5$ alt gruba ayrılmıştır $(\mathrm{n}=10)$. AAA uygulaması QUV cihazı yardımıla ultraviyole 1şı ve su spreyi altında 300 saat süreyle yapılmıştır. Örneklerin AAA yöntemi uygulanmadan önce ve uygulandıktan sonraki L*, a*, b* değerleri, kalibre edilmiş spektrofotometre kullanılarak kaydedilmiştir. Materyallerde oluşan renk farkı $\left(\Delta \mathrm{E}_{00}\right), \mathrm{L}^{*}, \mathrm{a}^{*}, \mathrm{~b}^{*}$ değerleri kullanılarak hesaplanmıştır. İstatistiksel analiz için Bonferroni Düzeltmesi yapılarak Kruskal Wallis ve Mann Whitney U Testleri kullanılmıştır (alfa=.05).

Bulgular: Mekanik parlatma tekniği $\mathrm{M}_{\mathrm{p}}$ örneklerde istatistiksel olarak en yüksek $\Delta \mathrm{E}_{00}$ değeri göstermiştir $(\mathrm{p}<.001)$. Aynı zamanda $\mathrm{E}_{\mathrm{p}}$ grubu örnekler $\mathrm{S}_{\mathrm{p}}$ grubu örneklerden istatistiksel olarak daha yüksek $\Delta \mathrm{E}_{00}$ değeri göstermiştir $(\mathrm{p}=.002)$. Glaze tekniği kullanılan örneklerde ise $\mathrm{S}_{\mathrm{g}}$ grubu örnekler $\mathrm{M}_{\mathrm{g}}$ grubu örneklerden istatistiksel

Deniz Yilmaz (四)

Öğr. Gör. Dr., Alanya Alaaddin Keykubat Üniversitesi Diş Hekimliği Fakültesi, Protetik Diş Tedavisi Anabilim Dall, Konaklı Mahallesi Mustafa Kemal Bulvarı No:82 Alanya/Antalya/Türkiye. e-mail:deniz.yilmaz@alanya.edu.tr

Lale Karaağaçlıŏlu

Prof. Dr., Ankara Üniversitesi Diş Hekimliği Fakültesi, Protetik Diş Tedavisi Anabilim Dal, Ankara, Türkiye

Burak Yilmaz

Doç. Dr., Bern Üniversitesi Diş Hekimliği Fakültesi, Rekonstruktif ve Gerodontoloji Anabilim Dall; Bern Üniversitesi Diş Hekimliği Fakültesi, Restoratif, Önleyici ve Pediatrik Diş Hekimliği Anabilim Dal, Bern, İsviçre Adjunct Prof. Dr., Ohio State Üniversitesi Diş Hekimliği Fakültesi, Restoratif ve Protetik Diş Tedavisi Anabilim Dall, Columbus, Ohio, ABD

31 Ekim-3 Kasım 2019 tarihinde Dalaman, Türkiye'de 24. Uluslararast Türk Prostodonti ve Implantoloji Derneği Bilimsel Kongresinde Sözlü Sunum (SS 0053) olarak sunulmuştur.

Submitted / Gönderilme: 24.09.2020

Accepted/Kabul: 08.06.2021 olarak daha yüksek $\Delta \mathrm{E}_{00}$ değeri göstermiştir ( $\left.\mathrm{p}=.005\right)$. Mekanik parlatma tekniği $\mathrm{M}_{\mathrm{p}}$ grubu örneklerde istatistiksel olarak en düşük $\Delta \mathrm{L}^{\prime}(\mathrm{p}=.003)$ değerini gösterirken $\mathrm{E}_{\mathrm{p}}$ grubu örneklerde en yüksek $\Delta \mathrm{C}^{\prime}(\mathrm{p}<.001)$ ve $\Delta \mathrm{H}^{\prime}(\mathrm{p}<.001)$ değerlerini göstermiştir. Glaze tekniği kullanılan örneklerde ise $\Delta \mathrm{L}^{\prime}\left(\mathrm{p}^{=}=.796\right), \Delta \mathrm{C}^{\prime}(\mathrm{p}=.218)$ ve $\Delta H^{\prime}(p=.529)$ değerleri açısından istatistiksel olarak anlamlı fark bulunmamıştır.

Sonuç: AAA işlemi mekanik parlatma tekniği kullanılan örneklerde Enamic materyalinde $\Delta \mathrm{C}^{\prime}$ ve $\Delta \mathrm{H}^{\prime}$ değerlerini yükseltirken, Mark II materyalinde $\Delta \mathrm{L}$ ' değerini düşürerek materyallerin kroma, renk tonu ve parlaklık değerlerini etkilemiştir.

Anahtar Kelimeler: CAD-CAM, renk, yaşlandırma

\section{Abstract}

Objectives: To evaluate the effect of glaze and polishing procedures on the color stability $\left(\Delta \mathrm{E}_{00}\right)$ of CAD-CAM blocks in different microstructures after accelerated artificial aging (AAA).

Materials and Methods: This study consisted of 3 main groups. Fifty specimens were fabricated from CAD-CAM blocks (Vita Mark II, Vita Suprinity and Vita Enamic) and after mechanical polishing or glaze finishing, the specimens $\left(\mathrm{M}_{\mathrm{p}}, \mathrm{M}_{\mathrm{g}}\right.$, $\mathrm{S}_{\mathrm{p}}, \mathrm{S}_{\mathrm{g}}, \mathrm{E}_{\mathrm{p}}$ ) were randomly divided into five subgroups $(\mathrm{n}=10)$. All specimens were exposed to ultraviolet light and water spray for 300 hours in the QUV test machine. After AAA application, $\Delta \mathrm{E}_{00}$ of materials was calculated. $\mathrm{L}^{*}, \mathrm{a}^{*}, \mathrm{~b}^{*}$ values were recorded using a calibrated digital spectrophotometer. The data were evaluated by using Kruskal Wallis Test and Mann Whitney U Test with Bonferroni corrections at the significance level of 0.05 .

Results: Polishing method resulted in statistically highest $\Delta \mathrm{E}_{00}$ for $\mathrm{M}_{\mathrm{p}}$ specimens $(\mathrm{p}<.001)$. Also $\mathrm{E}_{\mathrm{p}}$ specimens showed statistically higher $\Delta \mathrm{E}_{00}$ than $\mathrm{S}_{\mathrm{p}}$ specimens $(\mathrm{p}=.002)$. Glaze method resulted in statistically higher $\Delta \mathrm{E}_{00}$ for $\mathrm{S}_{\mathrm{g}}$ specimens than $\mathrm{M}_{\mathrm{g}}$ specimens $(\mathrm{p}=.005)$. Polishing method resulted in statistically lowest $\Delta \mathrm{L}^{\prime}$ for $\mathrm{M}_{\mathrm{p}}$ specimens $(\mathrm{p}=.003)$ and highest $\Delta \mathrm{C}^{\prime}(\mathrm{p}<.001)$ and $\Delta \mathrm{H}^{\prime}(\mathrm{p}<.001)$ for $\mathrm{E}_{\mathrm{p}}$ specimens. On the other hand there were no significant differences for $\Delta \mathrm{L}^{\prime}(\mathrm{p}=.796), \Delta \mathrm{C}^{\prime}(\mathrm{p}=.218), \Delta \mathrm{H}^{\prime}(\mathrm{p}=.529)$ for the glaze applied specimens.

Conclusions: Considering polishing tecnique AAA process increased the $\Delta C^{\prime}$ and $\Delta H^{\prime}$ values for Enamic material and decreased $\Delta \mathrm{L}^{\prime}$ values for Mark II material, consequently affecting chroma, hue and lightness values of the materials.

Keywords: CAD-CAM, color, aging 


\section{Giriş}

Diş hekimliğinde son 25 y1l içerisinde bilgisayar destekli tasarım ve üretim teknolojisi, (Computer Aided Design/Computer Aided Manufacturing, CAD-CAM) gelişmiş veri toplama ve üretim yeteneği sayesinde geniş bir kullanım alanı bulmuştur (Davidowitz \& Kotick, 2011). CAD-CAM teknolojisi, parsiyel ve tam kuronlar, hareketli parsiyel ve tam protezler, maksillofasiyal protezler, implant abutmentleri, hareketli ve sabit implant destekli protezlerin hazırlanmasında rutin olarak kullanılmaktadır.

Restorasyonların estetik görünümü ve kullanım süresi, materyalin renklenmemesine bağlıdır (Acar ve ark., 2016; De Oliveira ve ark., 2016). Restorasyonun renklenmeye karşı direnci, kırılma dayanımı ve diğer mekanik özellikleri kadar önemlidir. Restorasyonun renk stabilitesini koruyamaması ve renklenmesi restorasyonun yenilenmesini gerektirmektedir (Acar ve ark., 2016).

Bitirme teknikleri dental seramik restorasyonların renk stabilitesi ve estetiğinin sağlanmasında önemli bir rol oynamaktadır(Sarac veark.,2006).CAD-CAMsistemlerinde sinterlenmiş ve sinterlenmemiş seramik veya tamamen polimerize olmuş kompozit bloklar kullanılmaktadır. Bloklar millendikten sonra restorasyonların yüzey yapısı pürüzlüdür (Fasbinder \& Neiva, 2016), bu nedenle restorasyonların hastaya teslim edilmeden önce mekanik olarak parlatılması veya glaze yapılması zorunludur (Silva ve ark., 2014) Bu prosedürler yüzeyi daha pürüzsüz (Fasbinder \& Neiva, 2016) ve parlak (Lawson \& Burgess, 2016) hale getirir, plak retansiyonunu ve antagonist dişte aşınmayı azaltır (Preis ve ark.,2015). Böylece restorasyonun biyolojik komplikasyon insidansını düşürerek biyouyumluluğunu arttırır ve doğal dişle benzer kırılma ve yansıma karakteristiği sağlayarak milleme yöntemiyle elde edilen CAD-CAM restorasyonun estetik görünümünü geliştirir. (Fasbinder \& Neiva, 2016). Ayrıca parlak porselen yüzeyler, pürüzlü yüzeylere göre renklenmeye de daha dirençlidirler (Atay ve ark., 2009).

Çalışmanın amacı, farklı kompozisyonlardaki CADCAM bloklarına uygulanan mekanik parlatma ve glaze tekniklerinin, hızlandırılmış yaşlandırma işlemi karşısında renk değişimine etkisinin değerlendirilmesidir.

\section{Gereç ve Yöntemler}

Çalışmamız Ankara Üniversitesi Diş Hekimliği Fakültesi Araştırma Laboratuvarı ve T.C. Karayolları Genel Müdürlüğü Fizik Laboratuvarı’ nda yürütülmüştür.
İn vitro olarak yürütülen çalışmamızda $\mathrm{A} 2$ renginde Vita Mark II, Vita Suprinity ve Vita Enamic olmak üzere üç farklı CAD-CAM materyali kullanılmıştır. Kullanılan materyaller, bitirme teknikleri ve üretici firmalar Tablo 1' de gösterilmiştir.

Tablo 1. Kullanılan materyaller, bitirme teknikleri ve üretici firmalar

\begin{tabular}{|c|c|c|c|c|c|}
\hline Materyal & $\begin{array}{l}\text { Üretici } \\
\text { Firma }\end{array}$ & $\begin{array}{c}\text { Kimyasal } \\
\text { Kompozisyon }\end{array}$ & $\begin{array}{c}\text { Uygulanan } \\
\text { Bitirme } \\
\text { Tekniği }\end{array}$ & $\begin{array}{c}\text { Bitirme } \\
\text { Tekniğinde } \\
\text { Kullanılan } \\
\text { Materyaller }\end{array}$ & $\begin{array}{l}\text { Üretici } \\
\text { Firma }\end{array}$ \\
\hline \multirow[t]{2}{*}{ Mark II } & \multirow{5}{*}{$\begin{array}{c}\text { Vita } \\
\text { Zahnfabrik, } \\
\text { Bad } \\
\text { Säckingen, } \\
\text { Almanya }\end{array}$} & \multirow[t]{2}{*}{$\begin{array}{l}\text { Feldspatik } \\
\text { seramik }\end{array}$} & $\begin{array}{l}\text { Mekanik } \\
\text { Parlatma }\end{array}$ & $\begin{array}{l}\text { Vita Karat } \\
\text { Diamond } \\
\text { polishing } \\
\text { pasta }\end{array}$ & \multirow{5}{*}{$\begin{array}{c}\text { Vita } \\
\text { Zahnfabrik, } \\
\text { Bad } \\
\text { Säckingen, } \\
\text { Almanya }\end{array}$} \\
\hline & & & Glaze & $\begin{array}{l}\text { Vita Akzent } \\
\text { Glaze Pasta }\end{array}$ & \\
\hline \multirow[t]{2}{*}{ Suprinity } & & \multirow[t]{2}{*}{$\begin{array}{l}\text { Zirkonya ile } \\
\text { güçlendirilmiş } \\
\text { lityum silikat }\end{array}$} & $\begin{array}{l}\text { Mekanik } \\
\text { Parlatma }\end{array}$ & $\begin{array}{c}\text { Vita } \\
\text { Suprinity } \\
\text { Polishing } \\
\text { Set } \\
\text { Technical }\end{array}$ & \\
\hline & & & Glaze & $\begin{array}{l}\text { Vita Akzent } \\
\text { Glaze Pasta }\end{array}$ & \\
\hline Enamic & & $\begin{array}{l}\text { Hibrit seramik } \\
\% 14 \text { polimer } \\
\% 86 \text { seramik }\end{array}$ & $\begin{array}{l}\text { Mekanik } \\
\text { Parlatma }\end{array}$ & $\begin{array}{c}\text { Vita Enamic } \\
\text { Polishing } \\
\text { Set } \\
\text { Technical }\end{array}$ & \\
\hline
\end{tabular}

Kullanılan bloklar Micracut 201 doğrusal hassas kesim cihazı (Metkon, Bursa, Türkiye) kullanılarak $2 \mathrm{~mm}( \pm 0,1$ mm) kalınlığında su soğutması altında kesilmiștir. Kesme işlemi tamamlandıktan sonra örneklere dijital mikrometre (Mahr GmgH, Göttingen, Almanya) ile kalınlık testi yapılmış ve $12 \times 14 \times 2 \mathrm{~mm}$ boyutlarında toplam 50 örnek elde edilmiştir ve rastgele gruplara ayrılmıştır.

Birinci ana grup olarak Vita Mark II bloklardan elde edilen 20 örnek iki ayrı alt grupta değerlendirilmiştir. 10 örnekten oluşan alt gruplardan birincisine $\left(\mathrm{M}_{\mathrm{p}}\right)$ mekanik parlatma işlemi yapılmış, diğer 10 örnek $\left(\mathrm{M}_{\mathrm{g}}\right)$ ise üretici firmanın önerileri doğrultusunda glaze işlemine tabi tutulmuştur.

İkinci ana grup olarak prekristalize Vita Suprinity bloklar üretici firmanın önerileri doğrultusunda kristalize edildikten sonra elde edilen 20 örnek aynı şekilde iki ayrı alt grupta değerlendirilmiştir. 10 örnekten oluşan alt gruplardan birincisine $\left(\mathrm{S}_{\mathrm{p}}\right)$ mekanik parlatma işlemi uygulanırken, 10 örnekten oluşan diğer alt gruba ise üretici firmanın önerileri doğrultusunda glaze $\left(\mathrm{S}_{\mathrm{g}}\right)$ işlemi uygulanmıştır. 
Üçüncü ana grupta ise Vita Enamic bloklardan elde edilen 10 örneğe kimyasal kompozisyonunda bulunan \%14 polimer içeriği nedeniyle glaze işlemi uygulanamadığından üretici firmanın önerileri doğrultusunda sadece mekanik parlatma işlemi uygulanmıştır $\left(\mathrm{E}_{\mathrm{p}}\right)$.

Mekanik parlatma işlemi, örnek boyutlarına göre örnek yüzeyinde homojenite sağlamak amaciyla özel olarak üretilen akrilik rezinden üretilmiş bir kalıp üzerinde laboratuvarda mikro motor yardımı ile sabit devir ve sürede yapılmıştır. Parlatma materyalleri Tablo 1' de gösterildiği üzere üretici firmanın önerileri doğrultusunda her bir blok tipi için ayrı ayrı üretilen kendi özel laboratuvar tipi mekanik parlatma kiti aracılığı ile uygulanmıştır. Kullanılan materyaller ve uygulama süreleri Tablo 2' de gösterilmiştir. Mekanik parlatma işlemi örneklerin tek bir yüzeyine uygulanmıştır.

Tablo 2. Kullanılan materyaller ve uygulama süreleri

\begin{tabular}{|l|l|l|l|}
\hline Gruplar & Bloklar & $\begin{array}{l}\text { Kullanılan Mekanik } \\
\text { Parlatma Sistemi }\end{array}$ & Uygulama Süresi \\
\hline $\mathrm{M}_{\mathrm{p}}$ & Mark II & $\begin{array}{l}\text { Vita Karat Diamond } \\
\text { Polishing Pasta }\end{array}$ & $\begin{array}{l}\text { Pamuk firça polishing } \\
\text { pastası ile 60 saniye }\end{array}$ \\
\hline $\mathrm{S}_{\mathrm{p}}$ & Suprinity & $\begin{array}{l}\text { Vita Suprinity } \\
\text { Polishing Set } \\
\text { Technical }\end{array}$ & $\begin{array}{l}\text { Pembe lastik (pre - } \\
\text { polishing) ile 60 saniye } \\
\text { Gri lastik (high-gloss } \\
\text { polishing) ile 60 saniye }\end{array}$ \\
\hline $\mathrm{E}_{\mathrm{p}}$ & Enamic & $\begin{array}{l}\text { Vita Enamic } \\
\text { Polishing Set } \\
\text { Technical }\end{array}$ & $\begin{array}{l}\text { Pembe lastik (pre - } \\
\text { polishing) ile 60 saniye } \\
\text { Gri lastik (high-gloss } \\
\text { polishing) ile 60 saniye }\end{array}$ \\
\hline
\end{tabular}

Örneklere bitirme teknikleri uygulanmış, sonrasında ise ultrasonik temizleme cihazı (Whaledent Biosonic, Coltène/Whaledent Inc., Ohio, Amerika Birleşik Devletleri) kullanılarak 15 dakika distile su yardımıyla temizlenmiştir. Hazırlanan örnekler için renk tespit yöntemi olarak aletsel renk tespit yöntemi kullanılmıştır. Aletsel renk tespiti spektrofotometre cihazı ile yapılmış olup Vita EasyShade Advance (Vita Zahnfabrik, Bad Säckingen, Almanya) cihazı Single Tooth modunda kullanılmıştır. Renk tespitlerinin örneklerin aynı yüzünden ve aynı noktadan yapılması amaçlanmıştır. Aynı noktadan ölçüm yapabilmek için ise örneğin tam olarak yerleştiği arka plan rengi beyaz teflon bir sabitleme aygıtı geliştirilerek spektrofotometrenin 6 mm' lik ölçüm ucunun tam olarak örneğe birebir oturması sağlanmıştır. Cihazın kalibrasyonu renk ölçümlerinden önce yapılmış, her bir örnekten başlangıç renk ölçümleri $3 \mathrm{kez}$ tekrarlanarak CIE L*, a*, b* değerleri kaydedilmiştir. Her bir renk ölçümü D65 standart aydınlatma ortamına sahip renk ölçüm kutusunda yapılmış ve veriler kaydedilmiştir.

Başlangıç renk ölçümleri tamamlanan örneklere hızlandırılmış yaşlandırma işlemi uygulanmıştır. Yaşlandırma işlemi ISO 4892-3' e göre T.C. Karayolları Genel Müdürlüğü Fizik Laboratuvarı' nda bulunan QUV (Q-Panel Company, Cleveland, Amerika Birleşik Devletleri) yapay yaşlandırma cihazı kullanılarak yapılmışıtır. Lamba tipi II (UVB-313) altında $60{ }^{\circ} \mathrm{C} \pm 2{ }^{\circ} \mathrm{C}$ sıcaklıkta 8 saatlik 1şıma ve $50{ }^{\circ} \mathrm{C} \pm$ $2{ }^{\circ} \mathrm{C}$ sıcaklıkta 4 saatlik yoğunlaştırmadan oluşan döngüler tekrarlanarak 300 saat süreyle yapılmıştır.

Yaşlandırma işleminden sonraki renk ölçümleri ise $3 \mathrm{kez}$ tekrarlanarak yapılmış ve L*, a*, b* değerleri kaydedilmiştir.

Her bir örnek için hızlandırılmış yapay yaşlandırma işlemi sonrasındaki renklenme miktarlarının belirlenmesi için CIEDE2000 $\left(\Delta \mathrm{E}_{00}\right)$ renk farklılığı hesaplama formülü kullanılmıştır (Sharma ve ark., 2005). Tüm ölçümler tamamlandıktan sonra L*, a*, b* ölçümlerinin tekrarlarının ortalamaları alınarak renklenme miktarları aşağıdaki formül yardımıyla hesaplanmıştır:

$\Delta E_{00}=\sqrt{\left(\frac{\Delta L^{\prime}}{K_{L} S_{L}}\right)^{2}+\left(\frac{\Delta C^{\prime}}{K_{C} S_{C}}\right)^{2}+\left(\frac{\Delta H^{\prime}}{K_{H} S_{H}}\right)^{2}+R_{T}\left(\frac{\Delta C^{\prime}}{K_{C} S_{C}}\right)\left(\frac{\Delta H^{\prime}}{K_{H} S_{H}}\right)}$

$\Delta \mathrm{E}_{00}$ hesaplamalarında kullanılan $\Delta \mathrm{L}^{\prime}, \Delta \mathrm{C}^{\prime}, \Delta \mathrm{H}^{\prime}$ değerleri parlaklık, doygunluk ve renk tonundaki değişimleri ifade ederken RT (rotasyon fonksiyonu) ise mavi bölgedeki doygunluk ve ton farklılıkları arasındaki etkileşimin hesaplanmasında kullanılmaktadır. Ağırlık fonksiyonları SL, SC, SH ise L*, a*, b* koordinatlarındaki renk farklılık çiftlerinin lokasyonunu toplam renk farklılığ varyasyonuna uyumlandırmaktadır. Parametrik faktörler $\mathrm{KL}, \mathrm{KC}, \mathrm{KH}$ ise deney koşullarındaki düzeltme koşullarını ifade eder. Çalışmalarda genel olarak $\Delta \mathrm{E}_{00}$ renk farklılığ formülündeki parametrik faktörler 1 olarak alınmıştır (Sharma ve ark., 2005). Bu sistemle ilgili olarak Paravina ve arkadaşları algılanabilirlik eşik değerini $\Delta \mathrm{E}_{00}=0.8$ olarak, kabul edilebilirlik eşik değerini ise $\Delta \mathrm{E}_{00}=1.8$ olarak güncellemişlerdir (Paravina ve ark., 2015).

Verilerin analizi IBM SPSS Statistics 17.0 (IBM Corporation, Armonk, NY, USA) paket programı kullanılarak yapılmıştır. Sürekli sayısal değişkenlerin dağılımının normale yakın olup olmadığı Kolmogorov Smirnov testi ile varyansların homojenliği ise Levene testiyle araştırılmıştır. Tanımlayıcı istatistikler sürekli sayısal değişkenler için medyan (çeyrekler arası genişlik) 
şeklinde, kategorik değişkenler ise örnek sayısı ve (\%) biçiminde gösterilmiştir.

Gruplar arasında sürekli sayısal değişkenler yönünden farkın önemliliği bağımsız grup sayısı iki olduğunda Mann Whitney $U$ testiyle, ikiden fazla bağımsız grup arasındaki farkın önemliliği ise Kruskal Wallis testiyle değerlendirilmiştir. Kruskal Wallis test istatistiği sonuçlarının önemli bulunması halinde Conover' in çoklu karşıllaştırma testi kullanılarak farka neden olan durum(lar) tespit edilmiştir. Gruplar arasında kategorik değişkenler yönünden farkın önemliliği ise Olabilirlik Oran veya Fisher' in Kesin Sonuçlu Olasılık testi kullanılarak incelenmiştir. Aksi belirtilmedikçe $\mathrm{p}<0.05$ için sonuçlar istatistiksel olarak anlamlı kabul edilmiştir. Ancak, olası tüm çoklu karşılaştırmalarda Tip I hatayı kontrol edebilmek için Bonferroni Düzeltmesi yapılmıştır.

\section{Bulgular}

1. Tanımlayıcı İstatistikler ve $\Delta \mathrm{E}_{00}$ Değişimleri

Hızlandırılmış yapay yaşlandırma işlemi uygulanan örneklerden işlemden önce ve sonrasında $L^{*}, a^{*}$ ve $b^{*}$ değerleri ölçülmüş ve Tablo 3 ' te materyallere ve bitirme tekniklerine göre bu ölçümlerine ilişkin tanımlayıcı istatistikler gösterilmiştir.

Tablo 3. Materyal ve bitirme tekniklerine göre $L^{*}, a^{*}, b^{*}$ ölçümlerine ilişkin tanımlayıcı istatistikler

\begin{tabular}{|c|c|c|c|c|}
\hline & Mark II & Suprinity & Enamic & Genel \\
\hline \multicolumn{5}{|l|}{$\mathbf{L}_{1}$} \\
\hline Mekanik & $86.30(1.29)$ & $78.38(1.02)$ & 79.98 & $79.98(7.08)$ \\
\hline Parlatma & & & $(0.42)$ & \\
\hline Glaze & $84.60(1.78)$ & $78.53(1.03)$ & - & $81.18(6.12)$ \\
\hline Genel & $85.38(1.72)$ & $78.43(0.97)$ & $\begin{array}{l}79.98 \\
(0.42)\end{array}$ & $79.98(6.24)$ \\
\hline \multicolumn{5}{|l|}{$\mathbf{L}_{2}$} \\
\hline Mekanik & $85.08(1.15)$ & $78.55(0.81)$ & 79.70 & $79.70(5.87)$ \\
\hline Parlatma & & & $(0.58)$ & \\
\hline Glaze & $84.45(1.72)$ & $78.47(0.93)$ & - & $81.02(6.09)$ \\
\hline Genel & $84.75(1.14)$ & $78.47(0.77)$ & $\begin{array}{l}79.70 \\
(0.58) \\
\end{array}$ & $79.70(5.92)$ \\
\hline \multicolumn{5}{|l|}{$\mathbf{a}_{1}$} \\
\hline $\begin{array}{l}\text { Mekanik } \\
\text { Parlatma }\end{array}$ & $0.30(0.13)$ & $-1.00(0.20)$ & $\begin{array}{c}1.80 \\
(0.20)\end{array}$ & $0.30(2.70)$ \\
\hline Glaze & $0.40(0.10)$ & $-0.90(0.25)$ & - & $-0.30(1.30)$ \\
\hline Genel & $0.30(0.10)$ & $-0.90(0.10)$ & $\begin{array}{c}1.80 \\
(0.20)\end{array}$ & $0.30(1.30)$ \\
\hline
\end{tabular}

$\mathbf{a}_{2}$

$\begin{array}{lllll}\text { Mekanik } & 0.20(0.13) & -0.95(0.23) & 1.60 & 0.20(2.40) \\ \text { Parlatma } & & & (0.15) & \end{array}$

\begin{tabular}{lcccc} 
Glaze & $0.30(0.10)$ & $-0.90(0.08)$ & - & $-0.35(1.20)$ \\
Genel & $0.20(0.10)$ & $-0.90(0.17)$ & 1.60 & $0.20(1.20)$ \\
& & & $(0.15)$ & \\
\hline $\mathbf{b}_{1}$ & & & & \\
Mekanik & $18.77(0.88)$ & $19.43(2.73)$ & 19.85 & $19.43(1.12)$ \\
Parlatma & & & $(0.29)$ & \\
Glaze & $18.50(0.30)$ & $20.97(2.23)$ & - & $18.95(2.62)$ \\
Genel & $18.57(0.41)$ & $20.25(2.52)$ & 19.85 & $19.32(1.40)$ \\
& & & $(0.29)$ & \\
\hline b $_{2}$ & & & & \\
Mekanik & $18.20(0.95)$ & $19.05(3.30)$ & 20.00 & $19.05(1.65)$ \\
Parlatma & & & $(0.35)$ & \\
Glaze & $18.20(0.30)$ & $20.92(1.99)$ & - & $18.90(2.72)$ \\
Genel & $18.20(0.61)$ & $19.95(2.60)$ & 20.00 & $19.05(1.85)$ \\
& & & $(0.35)$ & \\
\hline
\end{tabular}

Veriler; medyan (çeyrekler arası genişlik) biçiminde gösterilmiştir.

$L^{*}, a^{*}, b^{*}$ değerleri ile renk farklılığ formülü kullanılarak renklenme miktarları $\left(\Delta \mathrm{E}_{00}\right), \Delta \mathrm{L}^{\prime}$, $\Delta \mathrm{C}^{\prime}$ ve $\Delta \mathrm{H}^{\prime}$ değeri hesaplanmış ve Tablo 4' te materyal ve bitirme tekniğine göre $\Delta \mathrm{E}_{00}, \Delta \mathrm{L}^{\prime}, \Delta \mathrm{C}^{\prime}$ ve $\Delta \mathrm{H}^{\prime}$ düzeyleri gösterilmiştir. Mekanik parlatma tekniği ile bitirilen materyaller arasında $\Delta \mathrm{E}_{00}$ düzeyleri yönünden istatistiksel olarak anlamlı fark olup $(\mathrm{p}<0.001)$ söz konusu farka neden olan durum Suprinity ve Enamic gruplarına göre Mark II grubunda renklenmenin daha fazla olmasidir $(\mathrm{p}<0.001$ ve $\mathrm{p}<0.001)$. Ayrıca, Suprinity grubuna göre Enamic grubunda da renklenme istatistiksel anlamlı olarak daha fazla gözlenmiştir $(p=0.002)$. Glaze tekniği kullanılan örnekler incelendiğinde Mark II materyaline göre Suprinity materyalinde $\Delta \mathrm{E}_{00}$ düzeyi istatistiksel anlamlı olarak daha yüksek bulunmuştur ( $\mathrm{p}=0.005$ ). Mekanik parlatma tekniği ile bitirilen Mark II materyalleri glaze tekniği ile bitirilen Mark II materyallerine göre istatistiksel anlamlı olarak daha fazla renklenme göstermiştir ( $\mathrm{p}<0.001)$. Mekanik parlatma tekniği ile bitirilen Suprinity materyallerine göre glaze tekniği ile bitirilen Suprinity materyallerinde istatistiksel anlamlı olarak daha fazla renklenme görülmüştür $(\mathrm{p}=0.005)$.

Mekanik parlatma tekniği ile bitirilen materyaller arasında $\Delta \mathrm{L}$ ' düzeyleri yönünden istatistiksel olarak anlamlı fark olup ( $\mathrm{p}=0.003$ ) söz konusu farka neden olan durum Suprinity ve Enamic gruplarına göre Mark II grubunda $\Delta \mathrm{L}$ ' düzeylerinin daha düşük olmasıdır $(\mathrm{p}<0.001$ ve $\mathrm{p}<0.001)$. Suprinity ve Enamic grupları arasında ise $\Delta \mathrm{L}^{\prime}$ düzeyleri yönünden istatistiksel olarak anlamlı fark görülmemiştir $(\mathrm{p}=0.107)$. Glaze tekniği ile bitirilen Mark II ve Suprinity materyalleri arasında $\Delta \mathrm{L}^{\prime}$ düzeyleri yönünden istatistiksel olarak anlamlı fark görülmemiştir $(\mathrm{p}=0.796)$. Mekanik parlatma tekniği ile bitirilen Mark II materyallerinin $\Delta \mathrm{L}^{\prime}$ 
düzeyleri glaze işlemi ile bitirilen Mark II materyallerine göre istatistiksel anlamlı olarak daha düşüktür $(\mathrm{p}=0.002)$. Mekanik parlatma tekniği ile bitirilen Suprinity materyalleri ile glaze işlemi ile bitirilen Suprinity materyalleri arasında $\Delta \mathrm{L}$ ' düzeyleri yönünden istatistiksel olarak anlamlı fark görülmemiştir ( $\mathrm{p}=0.218)$.

Tablo 4. Materyallere ve bitirme tekniklerine göre renk parametrelerinde meydana gelen değişimler

\begin{tabular}{|c|c|c|c|c|}
\hline & Mark II & Suprinity & Enamic & p-değeri † \\
\hline \multicolumn{5}{|l|}{$\overline{\Delta \mathbf{E}_{00}}$} \\
\hline Mekanik & $0.88(0.88)^{\mathrm{a}, \mathrm{b}}$ & $0.26(0.07)^{\mathrm{a}, \mathrm{c}}$ & $0.48(0.31)^{b, c}$ & $<0.0019$ \\
\hline \multicolumn{5}{|l|}{ Parlatma } \\
\hline Glaze & $0.23(0.19)$ & $0.36(0.13)$ & - & $0.005 \$$ \\
\hline p-değeri $†$ & $<0.001 \$$ & $0.005 \$$ & - & \\
\hline \multicolumn{5}{|l|}{$\Delta \mathbf{L}^{\prime}$} \\
\hline Mekanik & $-1.05(1.75)^{\mathrm{a}, \mathrm{b}}$ & $-0.05(0.32)^{\mathrm{a}}$ & $-0.08(0.58)^{\mathrm{b}}$ & 0.003 \\
\hline \multicolumn{5}{|l|}{ Parlatma } \\
\hline Glaze & $-0.27(0.41)$ & $-0.22(0.48)$ & - & $0.796 \$$ \\
\hline p-değeri $\ddagger$ & $0.002 \$$ & $0.218 \$$ & - & \\
\hline \multicolumn{5}{|l|}{$\Delta \mathrm{C}^{\prime}$} \\
\hline Mekanik & $-0.40(0.89)^{\mathrm{b}}$ & $-0.45(0.25)^{\mathrm{c}}$ & $0.23(0.37)^{b, c}$ & $<0.0019$ \\
\hline \multicolumn{5}{|l|}{ Parlatma } \\
\hline Glaze & $-0.28(0.18)$ & $-0.39(0.45)$ & - & $0.218 \$$ \\
\hline p-değeri $\ddagger$ & $0.280 \$$ & $0.912 \$$ & - & \\
\hline \multicolumn{5}{|l|}{$\Delta \mathbf{H}^{\prime}$} \\
\hline Mekanik & $0.13(0.25)^{\mathrm{a}, \mathrm{b}}$ & $0.01(0.13)^{\mathrm{a}, \mathrm{c}}$ & $0.33(0.22)^{b, c}$ & $<0,0019$ \\
\hline \multicolumn{5}{|c|}{ 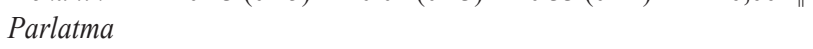 } \\
\hline Glaze & $0.13(0.03)$ & $0.03(0.16)$ & - & $0.529 \$$ \\
\hline p-değeri $\dagger$ & $0.353 \$$ & $0.190 \$$ & - & \\
\hline
\end{tabular}

Veriler; medyan (çeyrekler arası genişlik) biçiminde gösterilmiştir, $\uparrow$ Her bir bitirme tekniği içerisinde materyaller arasında yapılan karşılaştırmalar, Bonferroni Düzeltmesine göre $\mathrm{p}<0.025$ için sonuçlar istatistiksel olarak anlaml kabul edildi, $\$$ Her bir materyal içerisinde bitirme teknikleri arasında yapılan karşılaştırmalar, Bonferroni Düzeltmesine göre $\mathrm{p}<0.025$ için sonuçlar istatistiksel olarak anlamlı kabul edildi, ๆ Kruskal Wallis testi, \$ Mann Whitney U testi, a: Mark II ile Suprinity arasındaki fark istatistiksel olarak anlamlı ( $<<0.01)$, b: Mark II ile Enamic arasındaki fark istatistiksel olarak anlamlı ( $<<0.001)$, c: Suprinity ile Enamic arasındaki fark istatistiksel olarak anlamlı $(\mathrm{p}<0.01)$.

Mekanik parlatma tekniği ile bitirilen materyaller arasında $\Delta C^{\prime}$ ' düzeyleri yönünden istatistiksel olarak anlamlı fark olup $(\mathrm{p}<0.001)$ söz konusu farka neden olan durum Mark II ve Suprinity gruplarına göre Enamic grubunda $\Delta C$ ' düzeylerinin daha yüksek olmasıdır $(\mathrm{p}<0.001$ ve $\mathrm{p}<0.001)$. Suprinity ve Mark II grupları arasında ise $\Delta C^{\prime}$ düzeyleri yönünden istatistiksel olarak anlamlı fark görülmemiştir $(\mathrm{p}=0.777)$. Glaze tekniği ile bitirilen Mark II ve Supritiny materyalleri arasında $\Delta \mathrm{C}^{\prime}$ düzeyleri yönünden istatistiksel olarak anlamlı fark görülmemiştir $(\mathrm{p}=0.218)$. Mekanik parlatma tekniği ile bitirilen Mark II materyalleri ile glaze işlemi ile bitirilen Mark II materyalleri arasında $\Delta \mathrm{C}^{\prime}$ düzeyleri yönünden istatistiksel olarak anlamlı fark görülmemiştir $(\mathrm{p}=0.280)$. Mekanik parlatma tekniği ile bitirilen Suprinity materyalleri ile glaze işlemi ile bitirilen Suprinity materyalleri arasında $\Delta C^{\prime}$ düzeyleri yönünden istatistiksel olarak anlamlı fark görülmemiştir $(\mathrm{p}=0.912)$.

Mekanik parlatma tekniği ile bitirilen materyaller arasında $\Delta \mathrm{H}^{\prime}$ düzeyleri yönünden istatistiksel olarak anlamlı fark olup $(\mathrm{p}<0.001)$ söz konusu farka neden olan durum Mark II ve Suprinity gruplarına göre Enamic grubunda $\Delta \mathrm{H}^{\prime}$ düzeylerinin daha yüksek olmasıdır $(\mathrm{p}<0.001$ ve $\mathrm{p}<0.001)$. Ayrıca, Suprinity grubuna göre Mark II grubunun da $\Delta \mathrm{H}^{\prime}$ düzeyi istatistiksel anlamlı olarak daha yüksektir $(\mathrm{p}=0.003)$. Glaze tekniği ile bitirilen Mark II ve Suprinity materyalleri arasında $\Delta H^{\prime}$ ' düzeyleri yönünden istatistiksel olarak anlamlı fark görülmemiştir ( $\mathrm{p}=0.529$ ). Mekanik parlatma tekniği ile bitirilen Mark II materyalleri ile glaze işlemi ile bitirilen Mark II materyalleri arasında $\Delta \mathrm{H}^{\prime}$ düzeyleri yönünden istatistiksel olarak anlamlı fark görülmemiştir $(\mathrm{p}=0.353)$. Mekanik parlatma tekniği ile bitirilen Suprinity materyalleri ile glaze işlemi ile bitirilen Suprinity materyalleri arasında $\Delta H^{\prime}$ düzeyleri yönünden istatistiksel olarak anlamlı fark görülmemiştir $(\mathrm{p}=0.190)$.

\section{Materyallerden Bağımsız, Bitirme Tekniklerine Göre} $\Delta \mathrm{E}_{00}$ Değişimi

Tablo 5 incelendiğinde materyallerden bağımsız olarak bitirme tekniklerine göre renklenme miktarları incelendiği zaman mekanik parlatma ve glaze arasında $\Delta \mathrm{E}_{00}$ açısından istatistiksel olarak anlamlı fark bulunmuştur $(\mathrm{p}<0.05)$. Mekanik parlatma grubu, glaze grubuna göre daha çok renklenmiştir.

Tablo 5. Materyallerden bağımsız olarak bitirme tekniklerine

\begin{tabular}{cccc}
\multicolumn{4}{c}{ göre $\Delta \mathrm{E}_{00}$} \\
\hline & Mekanik Parlatma $(\mathbf{n}=\mathbf{3 0})$ & Glaze $(\mathbf{n}=\mathbf{2 0})$ & $\mathbf{p}$-değeri $\uparrow$ \\
\hline$\Delta \mathbf{E}_{00}$ & $0.41(0.47)$ & $0.32(0.14)$ & $\mathbf{0 . 0 3 8}$ \\
\hline
\end{tabular}

Veriler; medyan (çeyrekler arası genişlik) biçiminde gösterilmiştir, † Mann Whitney $U$ testi, $p<0.05$ için sonuçlar istatistiksel olarak anlaml kabul edildi.

\section{Tartışma}

Klinikte kullanılan CAD-CAM sistemleri, tek randevuda hekimlere restorasyonların tasarımını ve üretimini yapabilme olanağı sağlamaktadır. Ancak, üretim işlemi sonrasında gerekli olan pürüzsüz yüzeylerin elde edilmesi için seramik materyallerin, hastaya teslim edilmeden önce mutlaka 
bitirilme işlemlerinin gerçekleştirilmesi ve yüzeylerinin yeniden konturlanması gerekmektedir. Klinikte hasta başında uygulanan CAD-CAM restorasyonların parlatma işlemleri için mekanik parlatma ve glaze olmak üzere iki tip teknik bulunmaktadır (Fasbinder \& Neiva, 2016; Rashid ve ark., 2016).

Çalışmamız planlanırken CAD-CAM teknolojisinde kullanılabilen materyaller tercih edilmiştir. Dental materyaller dünyasında bu özelliklerde çok sayıda örneklere rastlanmaktadır. Bunlardan bazıları feldspatik seramikler, zirkonya ile güçlendirilmiş lityum silikat seramikler, hibrit seramikler, lityum disilikat seramikler, rezin nano seramikler ve kompozitler sayılabilir. Seçim yapılırken materyal özelliklerinin in vitro ve in vivo olarak literatür ile desteklenmesi göz önünde bulundurulmuş olup araştırmamızda standardizasyonu sağlamak amacıyla başlangıcından bitirme işlemine kadar kendi ürünlerinin kullanılmasını öneren firma tercih edilmiştir. Hem mekanik olarak parlatılabilen hem de glaze yapılabilen feldspatik seramik (Mark II) ve zirkonya ile güçlendirilmiş lityum silikat seramik (Suprinity) materyallerinin yanı sıra sadece mekanik olarak parlatılan hibrit seramik (Enamic) materyali tercih edilmiştir. $\mathrm{Bu}$ materyallere uygulanacak olan bitirme tekniklerinin renklenme üzerindeki etkisinin değerlendirilmesi ile klinik vakalar karşısında kullanılacak materyalin hangi teknikle bitirileceği konusunda netlik oluşturacağı düşünülmüşsür.

Çalışmamızda kullanılan klinik başarısı in vivo ve in vitro çalışmalar ile kanıtlanmış Mark II materyalinin özellikleri ve performansı, önceki araştırmalarda kapsamlı bir şekilde incelenmiş olup klinik olarak da yıllarca kullanılmış ve halen restorasyonlar üretilirken hangi CADCAM materyalinin tercih edileceği konusunda bir seçenek olarak karşımıza çıkmaktadır (Al-Harbi ve ark., 2017).

Suprinity materyali ise son yıllarda kullanıma sunulmuş ancak klinik başarısını destekleyen yeterli in vivo ve in vitro çalışma içermeyen bir materyal olarak karşımıza çıkmaktadır (Al-Harbi ve ark., 2017; Da Cunha ve ark., 2015; Sato ve ark., 2016). Cam seramiklerin optik özellikleri ve asitle pürüzlendirilebilmeleri nedeniyle, özellikle estetik veneer restorasyonlar için tercih sebebi olduğu Ozcan ve arkadaşlarının yaptığı bir derleme ile bildirilmiştir (Ozcan ve ark., 2012). Yakın zamanda ince grenli ve homojen bir mikro alt yapıya sahip zirkonya ile güçlendirilmiş lityum silikat cam seramikler anterior ve posterior kuronların yanı sira laminate restorasyonlar da dahil geniş bir uygulama alanında sahiptir (Da Cunha ve ark., 2015). Kompozisyonunda bulunan zirkonya, materyali güçlendiren bir kristal faz görevi görmekte ve çatlak yayılımını durdurmaktadır (Sato ve ark., 2016).

Çalışmamızda kullanılan bir diğer material, hibrit seramik olan \%14 polimer, \%86 seramik içeriğe sahip Enamic' dir. $\mathrm{Bu}$ materyalin klinik başarısı in vivo ve in vitro çalışmalar ile yakın dönemde incelenmiştir (Acar ve ark., 2016; AlHarbi ve ark., 2017). Materyal bünyesinde bulunan seramik ağ yapı üç boyutlu bir iskelet oluşturarak restorasyona gelen stresleri etkili bir şekilde dağıtır ve kırılmaya karşı direnç gösterir (Swain ve ark., 2016). Enamic materyalinde UDMA ve TEGDMA karışımı seramik ağa infiltre edilir. Materyal, seramik hacminin polimerden daha fazla olmasından dolayı literatürde hibrit seramik olarak geçmektedir (Mainjot ve ark., 2016).

Araştırmamızın temelini, kullanılan materyallerin renk değerlendirmeleri teşkil etmektedir. Saraç ve arkadaşlarının (2006) feldspatik porselenler üzerinde mekanik parlatma sistemlerinin renk ve yüzey pürüzlüğüne olan etkisini değerlendirdikleri çalışmalarında, mekanik parlatma sistemlerinin kabul edilebilir sınırlarda da olsa bir renk değişimine neden olduğunu bildirmişlerdir. $\mathrm{Bu}$ nedenle çalışmamızda başlangıç renk ölçümleri yüzey bitirme teknikleri uygulandıktan sonra yapılmıştır.

Genel olarak materyallerin optik özellikleri göz önüne alındığında restorasyon kalınlıkları önem taşımaktadır. Klinik olarak 1 ile $2 \mathrm{~mm}$ marjında seçilmesi konusunda doğrusal ya da üstel bir ilişkinin olup olmadığı belirsizdir (An ve ark., 2013). Buna ek olarak toplam kırılma indeksi doğrudan materyal kalınlığına bağlıdır. Kalınlığın arttırılması translusensinin azalmasına neden olur ve bu durum klinik açıdan değerlendirildiğinde son derece önemlidir (Awad ve ark., 2015). Niu ve arkadaşlarının (2013) yürüttükleri bir çalışmada, seramik restorasyonun kalınlığ 1,5 mm' nin üzerinde olduğunda estetik sonucun simante edilen core yapı ve siman renginden bağımsız olduğu ortaya çıkmıştır. $\mathrm{Bu}$ nedenle çalışmamızda tüm örnek kalınlıkları $2 \mathrm{~mm}$ olarak standardize edilmiş ve bitirme teknikleri örneklerin sadece bir yüzeyine uygulanarak tüm renk ölçümleri bu yüzeyden yapılmıştır.

Çalışmamızda örnek genişlikleri ve uzunlukları ise her bir örnek için 12x14 mm olarak standardize edilmiştir. ISO/TR 28642 (2011)' ye göre renk ölçümü yapılacak olan objenin boyutları önemlidir.

ISO/TR 28642 (2011)' ye göre renk ölçümlerinde kullanılabilen cihazlar spektrofotometreler, 
spektroradyometreler, kolorimetreler ve görüntüleme cihazlarıdır. Çalışmamızda renk ölçümleri için, literatürde de çok sayıda kullanılan spektrofotometre kullanılmıştır (Niu ve ark., 2014, Awad ve ark., 2015, Lawson \& Burgess, 2016). Translusent dental materyallerin renk ölçümleri, spektrofotometrenin veya kolorimetrenin renk ölçüm ucundaki küçük açılıktan yapılır ve edgeloss olarak bilinen 1şıma kaybı ile deviasyona uğrar (Chu ve ark., 2010). Edge-loss etkisini minimalize etmek için örnekler 6 mm' lik spektrofotometrenin ölçüm ucundan geniş olacak şekilde $12 \times 14 \mathrm{~mm}$ boyutlarında düz olarak hazırlanmıştır. Örnek genişlikleri ve uzunlukları Niu ve arkadaşlarının (2014), Awad ve arkadaşlarının (2015), Lawson ve Burgess' in (2016) yaptıkları çalışmalar ile de benzerdir. Standardizasyonu sağlamak ve edge-loss etkisini minimalize etmek amaciyla bütün ölçümlerde sabitleme cihazı kullanılmıştır.

ISO/TR 28642 (2011)' ye göre renk farkl1lıkları CIE tarafından tanımlanmış delta $\mathrm{E}(\Delta \mathrm{E})$ olarak isimlendirilmiştir. $\Delta \mathrm{E}$ hesaplanması için önerilen iki formül bulunmaktadır ve bunlar $\Delta \mathrm{E}^{*} \mathrm{ab}$ ve $\Delta \mathrm{E}_{00}$ ' dir. $1976 \mathrm{CIE} \mathrm{L^{* }} \mathrm{a}^{*} \mathrm{~b}^{*}$ renk koordinatları, renk değişiminin değerlendirilmesinde kullanılan geleneksel bir sistemdir. L* objenin parlaklığını, $a^{*}$ yeşil-kırmızı， b* mavi-sarı koordinatlarını temsil etmektedir. Bu koordinatlar, iki cisim veya iki örnek arasındaki renk farklılığının büyüklüğünün hesaplanarak klinik olarak algınabilirliklerini ve kabul edilebilirliklerini tanımlamak için kullanılmıştır (ISO/TR 28642:2016). Daha sonra 2001 yllında geliştirilen CIEDE2000 ise CIELAB formülüyle karşılaştırıldığında renk uzayının bazı bölgelerinde gelişmiş güvenilirlik faktörleri sunmaktadır. Kabul edilebilirlik ve algınabilirlik seviyeleri değerlendirilirken CIEDE2000 renk farklılığı hesaplama formülü CIELAB formülüne göre daha iyi uyum sağladığı bildirilmiştir (Ghinea ve ark., 2010). Özellikle dental seramiklerde küçük farklılıkları daha iyi hesaplamasından ve daha güncel olmasından dolayı çalışmamızda CIEDE2000 renk farklılığı hesaplama formülü kullanılmıştır. Ghinea ve arkadaşlarının 2010 yılında yaptıkları bir çalışma ile algılanabilirlik eşik değeri $\Delta \mathrm{E}_{00}=1.28$, kabul edilebilirlik eşik değeri ise $\Delta \mathrm{E}_{00}=2.24$ olarak belirlenmiş ve birçok çalışmada bu eşik değerler kullanılmıştır. Perez ve arkadaşlarının (2011) yaptıkları bir çalışmada kabul edilebilirlik eşik değerlerini $\Delta \mathrm{E}_{00}=1.87, \Delta \mathrm{L}^{\prime}=2.92, \Delta \mathrm{C}^{\prime}=2.52, \Delta \mathrm{H}^{\prime}=1.9$ olarak belirlemişlerdir. Paravina ve arkadaşlarının 2015 yılında yürüttükleri çalışmanın sonucunda ise, algılanabilirlik eşik değeri $\Delta \mathrm{E}_{00}=0.8$ iken kabul edilebilirlik eşik değeri ise $\Delta \mathrm{E}_{00}=1.8$ olarak bildirilmiştir. Yürüttüğümüz çalışmada ise daha güncel ve güvenilir olması nedeniyle Paravina ve arkadaşlarının bildirdikleri eşik değerler esas alınmıştır.

Daha önce de belirtildiği gibi çalışmamızda yüzey bitirme tekniği olarak üretici firmanın önerileri izlenmiştir. Her ne kadar mekanik parlatma süresi olarak üretici firma süre belirtmemiş ise de, CAD-CAM lityum silikat cam seramiklerin yüzey pürüzlülüğünü azaltmak için en etkili sistemin 60 saniye mekanik parlatma ve glaze pasta kullanımı olduğu bildirilmiştir (Fonzar, 2015). Yöntemin standardizasyonu amaciyla Mark II ve Enamic örnekler için de aynı teknikler ve süreler kullanılmıştır. Örnekler 60 saniye süreyle mekanik olarak parlatılmıştır ve durum literatürde Vita Polishing Set kullanılan çalışmalar ile uyumludur (Fonzar, 2015; Flury ve ark., 2017). Glaze işlemleri için üretici firma toz, sprey ve pasta önermektedir. Ancak tozun likitle manuel olarak karıştırılmasında ve bu karışımın yeniden aynı oranda hazırlanmasında veya spreyde ise basınç ve mesafe standardizasyonun sağlanmasının güç olması nedeniyle toz/likit oranını sabit tutmak ve standardizasyonu sağlamak amacıyla karıştırmaya gerek duyulmayan glaze pasta tercih edilmiştir.

Restoratif materyallerin renklenmesinde beslenme ile ilgili alışkanlıkların yanı sıra zamana bağlı yaşlanmanın önemli olduğu da bazı çalışmalarda belirtilmiştir. Birçok renklenme çalışması ağız çevresini daha iyi taklit etmek için UV 1şık altında nem ve 1şık döngülerini birleştiren hızlandırılmış yapay yaşlandırma prosedürlerini kullanmış, bazıları ise sadece suda bekletmenin yeterli olduğunu ifade etmişlerdir (Heydecke ve ark., 2001; Turgut \& Bagis, 2011; Bagis \& Turgut, 2013; De Oliveira ve ark., 2015; Karaokutan ve ark., 2016). Rezin simanların hızlandırılmış yapay yaşlandırma işlemi sonrasında renklenmesinin değerlendirildiği çalışmada $450 \mathrm{kj} / \mathrm{m}^{2}$ enerjiye kadar incelenmiş olup en fazla renk değişimi ilk $150 \mathrm{kj} / \mathrm{m}^{2}$, lik enerjide gözlenmiştir (Lu \& Powers, 2004). Çalışmamızda kullanılan yaşlandırma makinasının üreticisi 300 saat hızlandırılmış yapay yaşlandırma koşullarının 1 yıllık klinik kullanıma eşdeğer olduğunu bildirmektedir (Heydecke ve ark., 2001; Turgut \& Bagis, 2011) ancak bu durumun klinik olarak doğrulaması bulunmamaktadır (Turgut \& Bagis, 2011). Materyallerin klinik performansını ön görmeyi amaçlayan hızlandırılmış yapay yaşlandırma işlemi kısa zaman diliminde uzun süreli maruz kalmanın etkilerini simüle etme amaçlı olarak kullanılmakta olsa bile yapay olarak oluşturulan bu çevre koşulları tam olarak ağız içi koşulları taklit edememektedir (Karaokutan ve ark., 2016). 
UV radyasyonu, sıcaklık değişimleri ve su hem posterior hem de anterior restorasyonların hidrolize uğramasında ve materyalin yaşlanmasında rol alan başlıca çevresel faktörlerdir (Turgut \& Bagis, 2011). Hekimoglu ve arkadaşları (2000) hızlandırılmış yapay yaşlandırma işlemini 300 ile 900 saat arasında değişen sürelerde uygulamışlar ve 900 saat sonrasında bile kabul edilebilir sınırların üstünde bir renk değişikliği gözlememişlerdir. Ertan ve Şahin (2005) ise hızlandırılmış yapay yaşlandırma işlemine bağlı renk değişimlerinin ilk 100-300 saat arasında oluştuğunu bildirmişlerdir.

Çalışmamızda örnekler en fazla renk değişimin görüldüğü $150 \mathrm{kj} / \mathrm{m}^{2}$ lik enerji kullanılarak yaşlandırılmıştır. $\mathrm{Bu}$ durum literatür ile de benzerlik göstermektedir (Turgut \& Bagis, 2011; Bagis \& Turgut, 2013; Karaokutan ve ark., 2016). Turgut ve Bağış’ in (2011) laminate veneer restorasyonların renk stabilitesini değerlendirdikleri çalışmada, seramik örnekler 300 saat süreyle hızlandırılmış yapay yaşlandırma işlemine tabi tutulmuştur. Yaşlandırma işlemi sonrası örneklerde oluşan renklenmeler, klinik olarak kabul edilebilir sınırlarda olup gözle görülemez sınırlardadır. $\mathrm{Bu}$ durum çalışmamızla benzerlik göstermektedir. Çalışmamızın hızlandırılmış yapay yaşlandırma bulguları değerlendirildiğinde genel olarak tüm örnekler $\Delta \mathrm{E}_{00}=0.8$ algınabilirlik eşik değerinde veya altındadır. Renk farklılığ hesaplama formüllerindeki farklılıklar ve daha düşük sınırlarda güncel eşik değerlerin kullanılması Turgut ve Bağış’ in (2011) çalışması ile bizim çalışmamız arasındaki farklılıkları açıklayabilir.

Bağış ve Turgut (2013) hızlandırılmış yapay yaşlandırma işlemi öncesi ve sonrası farklı seramik materyallerin optik özelliklerini değerlendirmişlerdir. Araştırmacılar ultraviyole 1şık ve su spreyine maruz bırakılan örneklerin hızlandırılmış yapay yaşlandırma sonrası daha opak, koyu, kırmızımsı ve sarımsı hale geldiğini bildirmişlerdir. Örneklere 1 yıllık kullanıma eşdeğer 300 saat süreyle işlem döngüler halinde uygulanmıştır. Bununla birlikte örneklerde meydana gelen renklenmeler klinik olarak kabul edilebilir sınırlardadır. Bununla birlikte Dikicier ve arkadaşları (2014) lityum disilikat seramiklerin 200 saat süreyle yaşlandırılmasından sonra renklerinde koyulaşma görüldügünü ancak klinik olarak kabul edilebilir sınırlarda olduğunu rapor etmişlerdir. Tarafımızdan yürütülen çalışmada ise tüm örneklerin renklenme düzeyleri klinik olarak kabul edilebilir sinırlardadır. $\Delta \mathrm{L}^{\prime}, \Delta \mathrm{C}^{\prime}$ ve $\Delta \mathrm{H}^{\prime}$ parametreleri değerlendirildiğinde ise $\Delta \mathrm{L}^{\prime}$ parametresinde azalma yani materyallerin renginde koyulaşma, $\Delta \mathrm{C}^{\prime}$ parametresinde azalma ve $\Delta H^{\prime}$ parametresinde artış gözlenmektedir. $\Delta C^{\prime}$ 've $\Delta \mathrm{H}^{\prime}$ parametrelerindeki değişimler $\mathrm{a}^{*}$ ve $\mathrm{b}^{*}$ değerlerinden kaynaklanmaktadır.

Dental restorasyonların kullanıma bağlı renklenmesi önemlidir. Ancak renklenmedeki etkeni sadece buna bağlamak yetmemektedir. Yüzey bitirme özellikleri ve materyallerin kimyasal kompozisyonları gibi parametrelerin yanı sıra ağız ortamına ait değişik etkenlerin de göz önüne alınması gerekmektedir. Bu nedenle renk çalışmalarının in vitro ortamda yapılması bir fikir sahibi olmak için yeterli gibi görünse de in vivo çalışmalar ile desteklenmesi son derece önem taşımaktadır. $\mathrm{Bu}$ çalışmanın limitasyonu çalışmanın in vitro olarak yürütülmesi olup, yeni piyasaya sürülen materyallerle desteklenerek in vivo olarak yeni çalışmalar yapılması önerilmektedir.

\section{Sonuç}

Araştırmamız kapsamında kullandığımız materyaller ve yöntemlerle yaptı̆̆ımız in vitro çalışmamızın ışığı altında aşağıdaki sonuçlar elde edilmiştir:

1. Hızlandırılmış yapay yaşlandırma işlemi mekanik parlatma tekniği kullanılan örneklerde;

Enamic materyalinde $\Delta \mathrm{C}^{\prime}$ ve $\Delta \mathrm{H}^{\prime}$ değerlerini yükseltirken, Mark II materyalinde $\Delta \mathrm{L}$ ' değerini düşürerek materyallerin kroma, renk tonu ve parlaklık değerlerini etkilemiştir.

Mark II materyali en yüksek $\Delta \mathrm{E}_{00}$ değeri göstermiştir (klinik olarak kabul edilebilir seviyede).

2. Glaze tekniği kullanılan örneklerde; Suprinity materyali daha yüksek $\Delta \mathrm{E}_{00}$ değeri gösterirken (algılanabilir eşik değerden daha düşük), $\Delta \mathrm{L}^{\prime}, \Delta \mathrm{C}^{\prime}$ ve $\Delta \mathrm{H}^{\prime}$ değerlerini etkilememiştir.

\section{Teşekkürler}

$\mathrm{Bu}$ araştırma Ankara Üniversitesi Bilimsel Araştırma Projeleri Müdürlüğü'nün $\mathbf{1 6 L 0 2 3 4 0 0 5}$ proje numarası ile desteklenmiş̧tir.

\section{Referanslar}

1. Acar O, Yilmaz B, Altintas SH, Chandrasekaran I, Johnston WM. Color stainability of CAD-CAM and nanocomposite resin materials. J. Prosthet Dent. 2016;115(1):71-5. 
2. Al-Harbi FA, Ayad NM, Arrejaie AS, Bahgat HA, Baba NZ. Effect of Aging Regimens on Resin Nanoceramic Chairside CAD-CAM Material. J. Prosthodont. 2017;26(5):432-439.

3. An JS, Son HH, Qadeer S, Ju SW, Ahn JS. The influence of a continuous increase in thickness of opaque-shade composite resin on masking ability and translucency. Acta Odontol. Scand. 2013;71(1):120-9.

4. Atay A, Karayazgan B, Ozkan Y, Akyil MS. Effect of colored beverages on the color stability of feldspathic porcelain subjected to various surface treatments. Quintessence Int. 2009;40(7):e41-8.

5. Awad D, Stawarczyk B, Liebermann A, Ilie N. Translucency of esthetic dental restorative CAD-CAM materials and composite resins with respect to thickness and surface roughness. J. Prosthet. Dent. 2015;113(6):534-40.

6. Bagis B, Turgut S. Optical properties of current ceramics systems for laminate veneers. J. Dent. 2013;41(3):e24-30.

7. Chu SJ, Trushkowsky RD, Paravina RD. Dental color matching instruments and systems. Review of clinical and search aspects. J. Dent. 2010;38(2):e2-16.

8. Da Cunha LF, Mukai E, Hamerschmitt RM, Correr GM. Fabrication of lithium silicate ceramic veneers with a CADCAM approach: a clinical report of cleidocranial dysplasia. J. Prosthet. Dent. 2015;113(5):355-9.

9. Davidowitz G, Kotick PG. The use of CAD-CAM in dentistry. Dent. Clin. North. Am. 2011;55(3):559-70.

10. De Oliveira AL, Botta AC, Campos JA, Garcia PP. Effects of immersion media and repolishing on color stability and superficial morphology of nanofilled composite resin. Microsc. Microanal. 2014;20(4):1234-9.

11. De Oliveira DC, Ayres AP, Rocha MG, Giannini M, Puppin Rontani RM, Ferracane JL, Sinhoreti MA. Effect of Different In Vitro Aging Methods on Color Stability of a Dental Resin Based Composite Using CIELAB and CIEDE2000 ColorDifference Formulas. J. Esthet. Restor. Dent. 2015;27(5):32230 .

12. Dikicier S, Ayyıldiz S, Ozen J, Sipahi C. Effect of varying core thicknesses and artificial aging on the color difference of different all-ceramic materials. Acta. Odontol. Scand. 2014;72(8):623-9.

13. Ertan AA, Sahin E. Colour stability of low fusing porcelains: an in vitro study. J. Oral Rehabil. 2005;32:358-361.

14. Fasbinder DJ, Neiva GF. Surface Evaluation of Polishing Techniques for New Resilient CAD-CAM Restorative Materials. J. Esthet. Restor. Dent. 2016;28(1):56-66.

15. Flury S, Diebold E, Peutzfeldt A, Lussi A. Effect of artificial toothbrushing and water storage on the surface roughness and micromechanical properties of tooth-colored CADCAM materials. J. Prosthet. Dent. 2017;117(6):767-774.

16. Fonzar RF. A study into mechanical, aesthetic and adhesive aspects of lithia silica-based glass ceramics. Florentina Studiorum Universitas. Italy Ph.D. Thesis. 2015.

17. Ghinea R, Pérez MM, Herrera LJ, Rivas MJ, Yebra A, Paravina RD. Color difference thresholds in dental ceramics. J. Dent. 2010;38(2):e57-64.
18. Hekimoglu C, Anil N, Etikan. Effect of accelerated aging on the color stability of cemented laminate veneers. Int. J. Prosthodont. 2000;13(1):29-33.

19. Heydecke G, Zhang F, Razzoog ME. In vitro color stability of double-layer veneers after accelerated aging. J. Prosthet. Dent. 2001;85(6):551-7.

20. ISO/TR 28642:2016 Dentistry-Guidance on colour measurement.

21. Karaokutan I, Yilmaz Savas T, Aykent F, Ozdere E. Color Stability of CAD-CAM Fabricated Inlays after Accelerated Artificial Aging. J. Prosthodont. 2016;25(6):472-7.

22. Lawson NC, Burgess JO. Gloss and Stain Resistance of Ceramic-Polymer CAD-CAM Restorative Blocks. J. Esthet. Restor. Dent. 2016;28(1):S40-5.

23. $\mathrm{Lu} \mathrm{H}$, Powers JM. Color stability of resin cements after accelerated aging. Am. J. Dent. 2004;17(5):354-8.

24. Mainjot AK, Dupont NM, Oudkerk JC, Dewael TY, Sadoun MJ. From Artisanal to CAD-CAM Blocks: State of the Art of Indirect Composites. J. Dent. Res. 2016;95(5):487-95.

25. Niu E, Agustin M, Douglas RD. Color match of machinable lithium disilicate ceramics: Effects of cement color and thickness. J. Prosthet. Dent. 2014;111(1):42-50.

26. Ozcan M, Allahbeickaraghi A, Dundar M. Possible hazardous effects of hydrofluoric acid and recommendations for treatment approach: a review. Clin. Oral Investig. 2012;16(1):15-23.

27. Paravina $\mathrm{RD}$, Ghinea $\mathrm{R}$, Herrera $\mathrm{LJ}$, Bona $\mathrm{AD}$, Igiel $\mathrm{C}$, Linninger M, Sakai M, Takahashi H, Tashkandi E, Perez Mdel M. Color difference thresholds in dentistry. J. Esthet. Restor. Dent. 2015;27(1):S1-9.

28. Perez Mdel M, Ghinea R, Herrera LJ, Ionescu AM, Pomares H, Pulgar R, Paravina RD. Dental ceramics: a CIEDE2000 acceptability thresholds for lightness, chroma and hue differences. J. Dent. 2011;39(3):e37-44.

29. Preis V, Grumser K, Schneider-Feyrer S, Behr M, Rosentritt $M$. The effectiveness of polishing kits: influence on surface roughness of zirconia. Int. J. Prosthodont. 2015;28(2):14951.

30. Rashid H, Sheikh Z, Misbahuddin S, Kazmi MR, Qureshi $\mathrm{S}$, Uddin MZ. Advancements in all-ceramics for dental restorations and their effect on the wear of opposing dentition. Eur. J. Dent. 2016;10(4):583-588.

31. Sarac D, Sarac YS, Yuzbasioglu E, Bal S. The effects of porcelain polishing systems on the color and surface texture of feldspathic porcelain. J. Prosthet. Dent. 2006;96(2):122 8.

32. Sarac D, Sarac YS, Yuzbasioglu E, Bal S. The effects of porcelain polishing systems on the color and surface texture of feldspathic porcelain. J. Prosthet. Dent. 2006;96(2):1228.

33. Sato TP, Anami LC, Melo RM, Valandro LF, Bottino MA. Effects of Surface Treatments on the Bond Strength Between Resin Cement and a New Zirconia-reinforced Lithium Silicate Ceramic. Oper. Dent. 2016;41(3):284-92.

34. Sharma G, Wu W, Dalal EN. The CIEDE2000 ColorDifference Formula: Implementation Notes, Supplementary 
Test Data, and Mathematical Observations. Color. Res. Appl. 2005;30(1):21-30.

35. Silva TM, Salvia AC, Carvalho RF, Pagani C, Rocha DM, Silva EG. Polishing for glass ceramics: which protocol?. J. Prosthodont. Res. 2014;58(3):160-70.
36. Swain MV, Coldea A, Bilkhair A, Guess PC. Interpenetrating network ceramic-resin composite dental restorative materials. Dent. Mater. 2016;32(1):34-42.

37. Turgut S, Bagis B. Color stability of laminate veneers: an in vitro study. J. Dent. 2011;39(3):57-64. 